\title{
Materialism's Influence on Unsustainable Consumption Across Social Networking Sites: A Systematic Review
}

\author{
Alfonso Pellegrino*, Randall Shannon \\ College of Management, Center for Research on Sustainable Leadership of Mahidol University, Bangkok, Thailand \\ Email address: \\ alfonsopellegrino86@gmail.com (A. Pellegrino) \\ ${ }^{*}$ Corresponding author \\ To cite this article: \\ Alfonso Pellegrino, Randall Shannon. Materialism's Influence on Unsustainable Consumption Across Social Networking Sites: A Systematic \\ Review. International Journal of Business and Economics Research. Vol. 10, No. 4, 2021, pp. 125-140. doi: 10.11648/j.ijber.20211004.13
}

Received: June 28, 2021; Accepted: July 13, 2021; Published: July 21, 2021

\begin{abstract}
Research have revealed that consumers increasingly rely on information accessed through social networking sites as a guide for planning their future purchases. Furthermore, social networking sites content has been found to induce compulsive, conspicuous and impulse buying behaviors which are associated with overconsumption, economical, social and environmental issues. Social networking sites increase user's self-esteem which leads to low self-control eventually leading to irrational and unsustainable consumption behaviors. As social networking sites have become ubiquitous and they are having a big impact on people's lifestyle and overall on the planet, this research attempted to examine the relationship between materialism and unsustainable consumption behaviors over social networking sites users. The researchers looked at the results of the literature on materialism in social networking sites as well as three unsustainable behaviors: compulsive, conspicuous, and impulse-buying behavior. To discuss the problem and draw recommendations for policymakers and academics interested in the drafting of a possible research agenda, the authors conducted a systematic review of the literature. The Preferred Reporting Items for Systematic Reviews and Meta-Analysis (PRISMA) approach led the analysis, which was visualized using bibliometric mapping software (VOSViewer) based on peer reviewed journal articles present in the Scopus database. The findings revealed that there have been few research on materialism and its negative impact on consumption among social networking sites users. The paper concludes with a list of subjects that can be further investigated for future studies.
\end{abstract}

Keywords: Materialism, Unsustainable Consumption, Impulse Behaviour, Social Networking Sites, Social Media Consumption

\section{Introduction}

Consumers' unsustainable consumption patterns are often blamed on materialism [1-3]. Social networking sites influence consumer behaviour in multiple respects. For instance, digital shopping has evolved from shopping on websites to purchasing directly through social networking sites. Customers' feedback, social group suggestions, referrals, and ratings contribute to enhanced digital purchase engagement on social networking sites. Users can communicate and share knowledge within their peer network because of the rise in popularity of social networking sites [4]. Social networking sites users rely on a virtual community continuously sharing information. This is one type of social proof valuable and effective at increasing consumer trust [5]. Therefore, for brands to have a more engaged audience of potential consumers, it is paramount to foster trust, which can be obtained by using trusted sources or influencers [4]. While on social networking sites, users search for information and feedback before making any potential purchases, making reviews and users' comments a valuable source of information $[4,6]$. According to the Global Web Index in $2020,54 \%$ of active users have used social networking sites to research products.

Users' attitudes toward consumption and wealth can be shaped by frequent exposure to consumption-related information, especially among youngsters, who are more susceptible to media impact [7]. Individuals' beliefs about worldly possessions and financial success can be shaped by the content viewed on social networking sites; as a result, users who are frequently exposed to content and messages about acquisition and consumption may increase their 
materialism level and engage in more harmful consumption behaviours [8]. Unsustainable spending poses a risk to countries' economies, as individuals who take on too much credit or debt expose lenders, such as banks and financial organizations, to significant losses that in some cases become unrecoverable [9]. Continuous raw material extraction and product processing have a detrimental effect on the environment, with soil degradation, water scarcity, biodiversity loss, ecosystem function disruption, and global warming among the most severe repercussions [10]. Excessive production resulting from overconsumption frequently results in greenhouse gas emissions, pollution, and harm to ecosystems.

Within this research, the authors have reviewed the academic literature exploring the relationship between materialism and unsustainable consumption behaviours within social media social networking sites platforms with the objective to elucidate how social networking sites usage affects negative (also referred to as unsustainable) users' consumption patterns. Compulsive, impulse and conspicuous purchasing habits were investigated as they are referred to as harmful consumption behaviours [11]. These behaviours are driven partly by the role of materialism [12]. Studies on unsustainable consumption practices and social networking sites focus on the number of time users spend on social media sites, ignoring the importance of other aspects. Many studies have focused on constructs that enhance purchase intentions on social networking sites, specifically on creating value and revenue for brands. However, few studies have focused on the negative and unsustainable behaviours that social networking site users may develop as a consequence of more targeted ads [13, 14]. Recent research on Facebook advertisements [15] found that the information quality of the advertisement, users impulsiveness and the number of "likes" an ad receives can all influence customers' decision to buy impulsively. In this review, the authors explored the role played by materialism to attempt to explain the impact of social networking sites on negative behavioural consumption habits in a virtual environment. According to Thoumrungroje [16], research investigating the impact of online media attitudes toward paid and user-generated content on consumer spending behavior is either limited or scattered.

Although customers may not be consciously aware of it, their purchasing behaviour is highly influenced by what they see on social networking sites. Customers are aware that their newsfeeds are dominated by advertising [17]; however, they show no hesitation in clicking and exploring what they see [18]. For example, in a longitudinal study conducted by Blue Fountain Media in 2019 [19], with over 1000 regular social networking sites users between the ages of 18-55, it was found that purchase intentions are in favour of deals advertised daily on social networking sites. $70 \%$ of users liked clicking on ads and made purchases directly on the platforms. According to Wearesocial, a social networking sites marketing agency, in 2020, both Facebook and Instagram were the top clicked platforms for advertisements with $38 \%$ and $37 \%$, respectively, of the advertorial content clicked. $70 \%$ of social networking site users say they are more likely to click on advertising in their main news feed, while $65 \%$ claim they want social networking sites ads to show them items they are interested in and may not otherwise have noticed. The main research question that guided the study was:

RQ: "What does the literature say regarding materialism and the three unsustainable consumption behaviours within the social networking sites domain?"

To address this issue, the researchers systematically analyzed the literature to draw conclusions for policymakers and scholars involved in drafting a future research agenda. A systematic literature review was conducted to achieve this goal, using the Preferred Reporting Items for Systematic Reviews and Meta-Analysis (PRISMA) criteria. The research was divided into two categories based on whether they looked at the direct or indirect relationship between materialism and unsustainable spending habits. As a result, the focus of this review was on research that looked at materialism not as a consequence of unsustainable purchasing habits but as an antecedent to them.

\section{Unsustainable Consumption and Materialism: Definitions}

Unsustainable describes a rate of consumption that cannot be continued at its current rate [20]. Therefore, consumption behaviours that lead to debt or the depletionof too many resources can also be ascribed to unsustainable consumption patterns. Sustainability is an "emerging megatrend" which many consumers claim has high importance in their daily consumption habits [21]. For example, reducing waste and saving natural resources such as water, oil, or tropical rainforests is essential. Simultaneously consumers are also engaged in unsustainable consumption behaviours, such as using a car instead of public transportation or buying products based on a highly resource-intensive manufacturing process [22]. When related to consumption, the word unsustainable applies to something that cannot be sustained at its current pace into the future. The consequences on individuals may be economical (e.g., debts, credit card over usage, mental disorders, and addiction), environmental (e.g., resourceintensive products, pollution), and social (e.g., labour intensity and labour exploitation). Unsustainable consumption behaviours may hamper the well-being of future generations. Research in the psychology domain on compulsive, conspicuous, or impulsive buying behaviour has historically focused on its harmful effects for individuals and their well-being [23]. However, there is a paucity of research on sustainability and its relation to excessive consumption in the sustainable marketing literature. The few existing studies have mainly involved small samples of participants [24] or an anti-consumerist orientation [25]. Therefore, it is evident that consumption's "dark side" has received little attention in the marketing 
literature. Although over-consumption and related principles, such as excessive, impulsive, or compulsive buying behaviours, have been discussed in the sustainable marketing literature, the key objective has been on the negative financial impacts on consumers rather than the social impact social networking site have over their users [26].

\subsection{Materialism}

According to Belk [27], materialism is a consumer orientation that reflects the importance that a consumer attaches to worldly possessions. Table 1 summarizes the most relevant definitions concerning materialism found in the literature.

Table 1. List of relevant research on materialism

\begin{tabular}{ll}
\hline Authors & Materialism Core Findings \\
\hline $\begin{array}{l}\text { Churchill Jr and } \\
\text { Moschis [28] }\end{array}$ & $\begin{array}{l}\text { Materialism is an ideology that emphasizes artefacts and money for personal gratification and social advancement. Their work } \\
\text { focused on understanding teenage consumers' socialization, including materialism comprehension. } \\
\text { There are two forms of materialism, depending on the consumption purposes: Instrumental and terminal. Instrumental materialism refers to } \\
\text { the acquisition and possession of material objects that have the potential to enhance individual health, longevity, and happiness, whereas }\end{array}$ \\
$\begin{array}{l}\text { Csikszentmihalyi } \\
\text { and Halton [29] }\end{array}$ & $\begin{array}{l}\text { terminal materialism refers to obtaining and possessing material objects for their own sake. The first is harmless, whereas the second is } \\
\text { negative. }\end{array}$ \\
Richins and & $\begin{array}{l}\text { Materialism includes three aspects: Acquisition as a pursuit of happiness, possession-defined accomplishment, and } \\
\text { acquisition/possession centrality. }\end{array}$ \\
Dawson [30] & $\begin{array}{l}\text { Materialism is seen as a function of both intrinsic and extrinsic objectives. Intrinsic goals such as self-acceptance and physical fitness } \\
\text { refer to goals that are ideally beneficial to attain because they are likely to fulfil intrinsic psychological needs (e.g., autonomy, } \\
\text { competency, and connectivity). In contrast, extrinsic goals (e.g., money and fame) apply to external goals to overcome insecurities. } \\
\text { Masser and }\end{array}$ \\
Mhuvia [31] &
\end{tabular}

Materialism, according to Shrum, is the amount to which individuals strive to establish and maintain the self through the acquisition and use of goods, services, experiences, or relationships that are believed to have desirable symbolic value [32]. Vedder [33] wrote, in the second half of the twentieth century, that materialists were individuals who worshipped objects and whose pursuit of possessions took the role of religion in structuring their lives and orienting their actions. Materialism was then described as "an inclination emphasizing possessions and money for personal satisfaction and social progress" [34]. For Daun, materialism is a way of life aimed at consuming material goods. Consumption, he claims, becomes a yardstick and a point of contrast for social comparisons in a materialistic way of life.

The initial effort to define materialism's nature, background and harmful effects was made by Belk [28] in 1985. Belk conceived materialism as the manifestation of three personality characteristics: Greediness, non-generosity, and envy. By measuring these three features, materialism can be determined; possessiveness is defined as the desire to own or control one's property, non-generosity is viewed as a reluctance of an individual to share their belongings with others, and jealousy is defined as a desire for someone else's wealth.

This concept differs from others in that it:

1) Describes the underlying motivations of materialism in terms of the creation and maintenance of selfidentity.

2) Defines materialism in terms of the acquisition, which includes not only the purchase but also the acquisition of gifts, inherited wealth, and other nonpurchase means.

3) Integrates the use of the acquisitor.
4) Includes not just commodities and services, but also activities, experiences (such as holidays and sporting events), and connections (such as friendships and marriages).

5) Refers to the symbolic nature of the acquisitions and hence the degree to which they were made [35].

In 1992, Richins and Dawson [30] moved materialism research in a new direction, defining materialism as a feature of the value placed upon material goods. The greater one's level of materialism, the greater the value placed on material possessions in someone's life. "A collection of centrally held views about the value of possessions in one's life" is how materialism is defined. Material possessions, according to this belief, are:

1) A major goal of life.

2) A path to happiness.

3) A yardstick upon which to evaluate success.

Richins and Dawson's definitions have been viewed as a complement to Belk's work, as both have addressed qualitative issues (personality \& consumer value, respectively). Materialism, according to Belk, focuses on endogenous personality traits that make up an individual's personality. Instead, Richin and Dawson's measurement focuses on exogenous personal values (not societal values) influenced by the person's surroundings. Kasser and Ryan [36] also argued that materialism is a feature of one's life's intrinsic and extrinsic ambitions. Anything that one aspires to is limited to materialistic goals. According to O'Neil [37], materialism is a condition marked by a desire for material objects.

Materialists suffer from various addictions, psychological wounds, neuroses, and personality problems, many of which are caused or exacerbated to a degree by the desire for money and objects. Millar and Thomas [38] investigated the influence of materialism on the relationship between 
happiness and material purchases. They discovered that materialistic people are more likely than non-materialistic persons to associate satisfaction with material acquisitions. This highlighted the positive influence of consumerism on life satisfaction. Others have extensively denounced consumerism as a factor that reduces life satisfaction. Tsang, Carpenter, Roberts, Frisch and Carlisle [39] found that materialistic behaviour leads to unhappiness in people's lives. Shrum, Wong, Arif, Chugani, Gunz, Lowrey and Scott [40] contributed to the idea of materialism's disposition of individualism. They defined materialism as searching for material goods to maintain one's identity that is defined by the material goods one possesses.

Cleveland, Laroche and Papadopoulos [41] stated that the values of materialism might differ across the context of consumption behaviours because individuals associate different meanings with branded things. Different financial, political, and institutional variables might cause such discrepancies [42]. In another study, Eastman et al. [43] discovered that, while consumers' responses to materialism and luxury goods purchasing were consistent across cultural and economic conditions, respondents' levels of materialism varied among countries. According to Wong et al. [44], Hong Kong customers with higher socioeconomic classes are more likely to improve their self-image and lifestyle. Lerman and Maxwell [45] discovered that Russian immigrants in the United States, who came from a non-consumer culture at the time of immigration, did not differ in materialism rates from American consumers.

\subsection{Compulsive Shopping Behavior}

O'Guinn and Faber [46] described compulsive buying behaviour as chronic, repetitive purchasing that becomes a primary response to unpleasant events or emotions, with the primary goal of restoring a positive mood. A previous study has found that heavy internet usage, particularly through social media platforms, have a major impact on compulsive purchases [47]. When applied to the virtual environment, the social comparison theory [48] can help explain social media sites dynamics better. In this environment, teenagers compare aspects of their lives to others, typically for self-evaluation and self-improvement, and they even create their desired identity.

Excessive or poorly controlled fears, desires, or actions related to shopping and spending characterize compulsive purchase behaviour, which can have negative repercussions. This behaviour has progressively increased among young adults in recent decades, and it can be triggered by sociological, psychological, and biological reasons. According to Dittmar and Drury [49] and Xu [50] excessive involvement in uncontrollable shopping reveals compulsive customers' materialistic impulses. Compulsive consumers buy products for various reasons, including gaining social status as a tangible symbol of their success.

Compulsive purchasing can be defined as a persistent drive to buy products over own desires and means. Other researchers agree that compulsive shopping is a manifestation of an uncontrollable drive to purchase [51]. Most definitions of compulsive purchasing include uncontrollable, negative spending urges. Teenagers were shown to be more obsessive than adults, according to Dittmar [52]. Compulsive buying, according to Faber [53], is an attempt to avoid self-consciousness. The idea defined by Faber was the principle of escape to explain why so many people engage in potentially self-destructive conduct. According to the escape theory, certain persons may suffer negative consequences due to self-awareness. People focus their attention on a particular object to avoid negative emotions, and being involved in the purchase might help people block out negative thoughts and feelings about themselves.

For obsessive consumers, shopping and spending are allconsuming activities, with little regard for the long-term negative repercussions of such behaviour (e.g., little or no savings, credit card difficulties, interpersonal issues, and feelings of humiliation, guilt, remorse, and hopelessness) [54]. As can be seen from the definitions above, compulsive shopping is likely to have a negative impact on life satisfaction. Mazarin and Moore [55] discovered that excessive internet use impacted young male adults' identity development. Excessive use of social media sites causes identity "fragmentation," which leads to more intense online compulsive shopping (i.e., to fill the gaps between their current fragmented identities and the ideal identities to which they are aspiring).

\subsection{Conspicuous Buying Behavior}

Conspicuous buying is another unsustainable consumption behavior defined as the act of showing and purchasing expensive and luxury items or services motivated by social factors, such as impressing others, improving individuals' social status, and gathering prestige through objects rather than quality features [56]. On social networking sites accounts, consumers share products and brands that display wealth and that satisfy a person's need for prestige [12]. This information makes users feel good and more accepted among their friends, as well as it attracts positive feedback, which boosts a person's self-esteem and ultimately provides several positive social benefits and increases well-being, therefore enhancing materialism in users [57].

Buying luxury products is often labeled as conspicuous buying behavior. The first theory was initially framed and developed by Veblen's [58] research. The previous literature acknowledged the influence of social factors that push people to conspicuously consume products. Two main factors are typically regarded as the drivers of people's appreciation of material goods and, therefore, their willingness to spend money on conspicuous products. The first element refers to feelings of insecurity, whereas the second shifts toward individuals' materialistic consumption attitudes. Considering the substantial theoretical and empirical similarity between conspicuous buying behavior and materialism [12], the authors assume that both constructs are strictly interrelated.

Flynn and Eastman [59] reported that the desire to achieve 
a status or social recognition through the purchase and consumption of products is a significant driving factor affecting a broad range of consumer behaviors. In other words, consumers buy certain goods in the hope that society will view them more favorably [12].

\subsection{Impulse-Buying Behavior}

Impulse buying is defined as a consumption activity that occurs as a result of the instant stimulus and occurs without intentional evaluation of the purchase's potential outcomes [60]. Users who manipulate others by uploading photographs of their purchases and offer recommendations tend to influence this behaviour on social networking sites platforms. These actions encourage unexpected and impulse purchases and materialistic attitudes among users of social networking sites; when a person's desire win over their super-ego, which strives to resist the short-term drive to purchase products without conscious consideration, impulse buying occurs naturally [12].

Consumers seem to demonstrate greater impulse-buying behaviours in recent decades due to an increase in disposable income, a change in social position and increased access to credit. Shopping time limits, customer sex, product quality, customer emotional state, and level of familiarity with the store layout [61] are all factors that influence impulse purchase behaviour. While impulse buying behavior might be regarded as a leisure activity, it can also have negative implications such as debt, stress, and anxiety [12].

\section{Methods}

\subsection{Identification of Documents}

The current review was guided by the PRISMA approach [62]. The first step was to identify all the articles published concerning social networking sites, materialism and negative consumption behaviours. The authors identified the most relevant journal articles, conference papers, and books regarding social networking sites, materialism, and unsustainable consumption behaviours in the Scopus Journal directory. Scopus was used as the reference database for this research to find pertinent documents. Scopus provides access to bibliographic data used in bibliometric digital mapping software [63] and a broad range of subjects deemed relevant to social networking sites and consumption. While Web of Science has a comparable capacity for exporting meta-data for bibliometric analysis, Scopus' coverage of social science disciplines is substantially more extensive [64].

The researchers followed the guidelines suggested by Kitchenham and Charters [65] for this review. To obtain primary peer-reviewed research, an automated search was undertaken utilizing the Scopus databases to answer the review's research question, using keywords acquired from the following sentinel publications [66-69]. The keywords of interest were searched for research titles to define boundaries for what publications would be included in the review. A combination of common social networking sites and unsustainable consumption keywords were utilized to search through the selected database to match identified keywords with published research and relevant literature. This procedure aimed to find as many relevant publications as possible in the fields of materialism, social networking sites, and unsustainable consumption.

Our first search focused on the keywords (TITLE-ABSKEY ("materialism") OR TITLE-ABS-KEY ("compulsive buying") OR TITLE-ABS-KEY ("conspicuous buying") OR TITLE-ABS-KEY ("impulse buying") AND TITLE-ABSKEY ("Social Media"). This search produced 71 documents. We assessed all document abstracts for eligibility and selected 29 documents. We then conducted additional searches and assessed all document abstracts for eligibility to have a wider pool of articles carrying out our bibliometric review.

1) The search on (TITLE-ABS-KEY ("Social Media") AND TITLE-ABS-KEY ("materialism") AND TITLE-ABSKEY ("unsustainable consumption") yielded 39 documents, from which we selected 24 as eligible, eliminating irrelevant documents and duplicates.

2) The search TITLE-ABS-KEY ("Social Media") OR TITLE-ABS-KEY ("Social Media Marketing") OR TITLEABS-KEY ("Social Networking Sites" AND ("materialism") AND ("compulsive buying") OR ("conspicuous buying") OR ("impulse buying") OR ("unsustainable consumption") produced five documents of which 3 were duplicates, and only two were eligible.

These three research led to 56 eligible documents, which were grouped as very relevant documents. However, these were too few to carry out comprehensive bibliometric research therefore, the researchers decided to include consumer behaviour among the keywords.

3) (TITLE-ABS-KEY ("Social Media") AND ("materialism") AND ("compulsive buying") OR ("conspicuous buying") OR ("impulse buying") OR ("unsustainable consumption") OR ("consumer behaviour") OR ("unsustainable behaviours") that produced initially 4 documents of which 1 was eligible after excluding duplicates and non-relevant documents.

Eventually, the following keywords combination resulted in the highest number of relevant articles (43): "social media" AND "materialism" OR "unsustainable behaviours." The researchers combined all the relevant articles found in the previous digital searches and eventually identified 56 articles, which highlights the recent scholarly interest in the field examined. The authors, therefore, decided to add all the articles in which social networking sites was also linked to "consumer behaviour" OR "materialism" OR "compulsive" OR "impulse" OR "conspicuous." This yielded 864 documents, which allowed the authors to carry out more comprehensive bibliometric research. Ineligible source categories such as editorials, book reviews, research notes, correspondence, and duplicate items were deleted during the initial screening of documents. Then the researchers examined the titles and abstracts to see if they were relevant to the topics treated. There were two common grounds for 
document exclusion. First, while several documents emphasized materialism in relation to sustainability, the studies were not focusing on digital media or social networking sites. Similarly, overconsumption and negative consumption habits were discussed in relation to sustainability in several studies, although only in broad terms.

Documents that belonged to engineering, medicine, and mathematics subject areas were excluded because these articles were not relevant to this research; this left a total of
660 documents. Articles were then limited only to journal articles, conference papers, reviews, books, and only those published in English. This process excluded 52 additional documents. Then, the relevance of the remaining articles was finally checked by reading the titles, abstracts, and keywords. Documents were excluded if social networking sites was only mentioned as a background topic or very generally. This screening process left a final database of five hundred and ninety-three eligible documents.

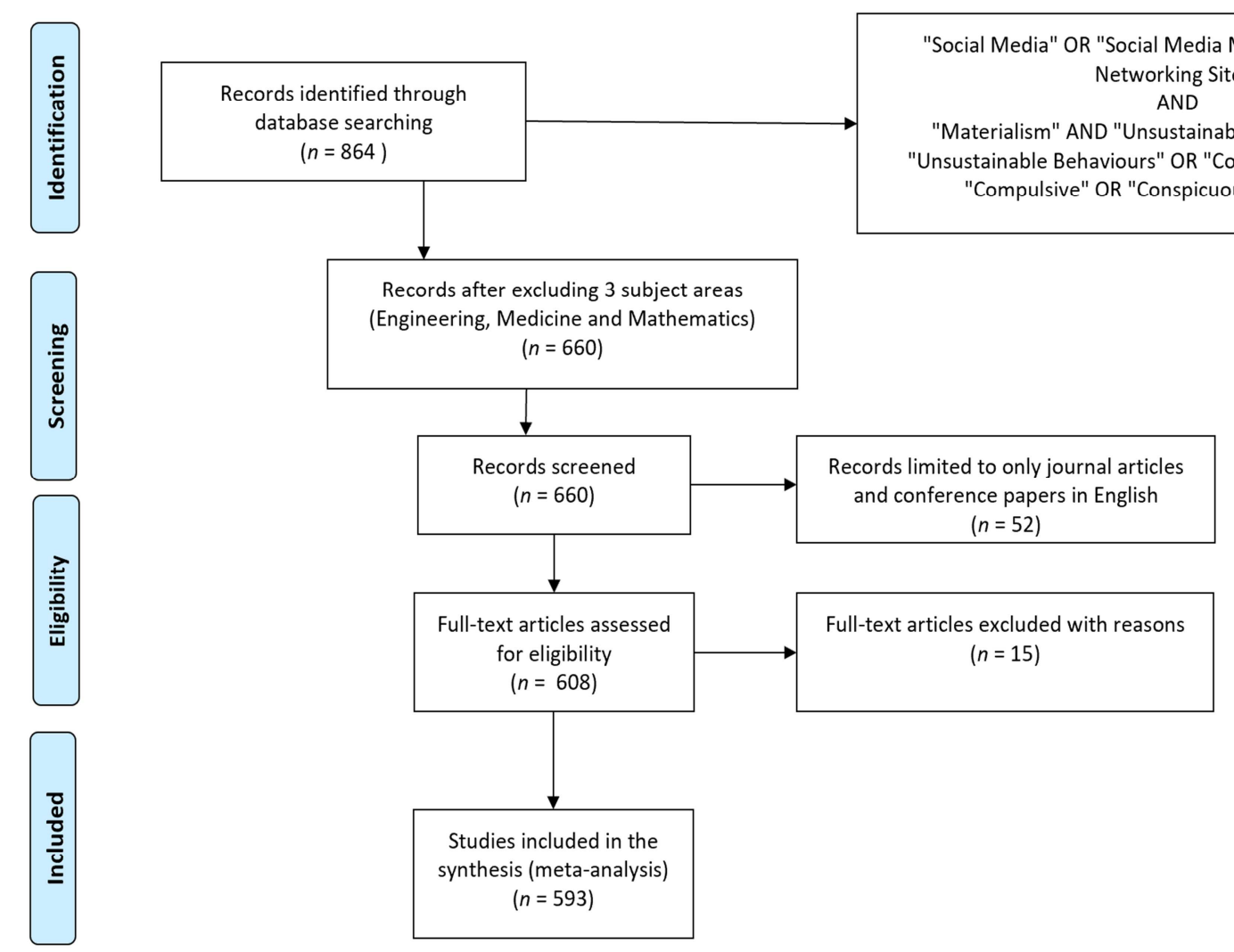

Figure 1. Preferred Reporting Items for Systematic Reviews and Meta-Analysis (PRISMA) flowchart showing the search procedures used in the review.

\subsection{Data Analysis}

After identifying 593 Scopus files, bibliographic data related to these documents were imported into an Excel sheet where the authors' names, their affiliations, document titles, keywords, abstracts, and citation figures were analyzed. These were subsequently uploaded into VOSViewer software version 1.6.8 to begin the bibliometric review. Descriptive statistics were created to define the whole body of knowledge about social networking sites in relation to materialism and consumer behaviour. VOSViewer was used to analyze citation, co-citation, and keyword co-occurrences. According to Zupic and Čater [70], co-citation analysis measures the influence of documents, authors, and journals heavily cited and thus considered influential. Co-citation analysis has the objective to build similarities between authors, journals, and documents and is generally defined as the frequency with which two units are cited together within the reference list of a third article [71].

\section{Results}

This section of the study includes findings on materialism, social media, and unsustainable consumption behaviours. The results are presented by the foci outlined in the study questions.

\subsection{Volume, Growth Trajectory and Geographic Distribution of the Literature}

After performing the Scopus-based investigation of the current literature regarding social networking sites, materialism, and consumer behaviours, the researchers obtained a knowledge base consisting of 593 documents comprising 425 journal articles, 118 conference papers, 27 articles reviews, 12 books and 11 conference reviews. The included literature was very recent. As shown in Figure 2, it slowly started in 2009 before spiking in 2014; after that, 
production gradually increased each year until a peak was reached in 2020 with 153 publications. By analyzing the literature published during the past decade, it was observed that the exponential increase in scholarly production on social networking sites, materialism, and unsustainable consumer behaviour might be due to the increasingly widespread introduction of social networking sites and the diffusion of digital marketing, which have fundamentally impacted consumer behaviours [72].

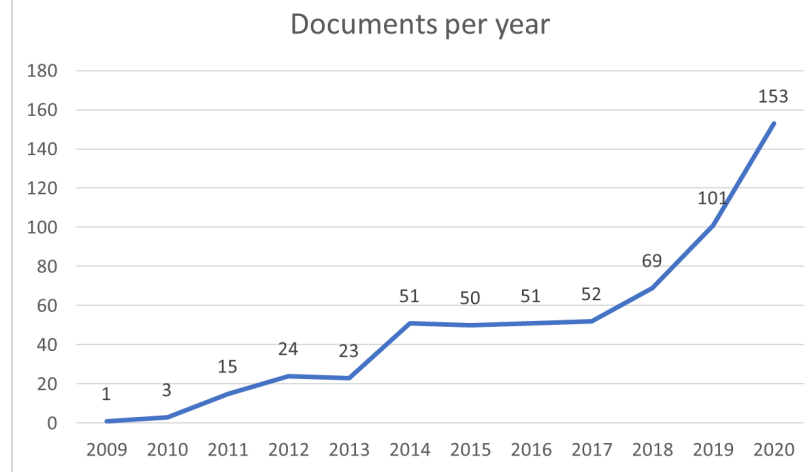

Figure 2. Annual volume of social networking sites in relation to materialism, social networking sites, and unsustainable consumer behavior publications $(n=593)$.

The geographical distribution trends on social networking sites, materialism, and consumer behaviour scholarly production are highlighted in Figure 3. The figure shows that the most productive countries are the USA (162), the U.K. (68), and China (41), which produced 271 articles, equal to $45 \%$ of the entire scholarly production examined in this bibliometric analysis. China has slowly evolved in various ways with the growth of the Internet and social networking sites. Unsurprisingly, Anglo-American scholarly production on social networking sites, materialism, and consumer behaviour have led the research output. In the USA, according to a survey conducted in early 2019, approximately $7 / 10$ adults (69\%) use Facebook. This figure remained unchanged from April 2016 but increased by 54\% from that of August 2012. It is interesting to observe that social networking sites studies are attracting many researchers in Asian countries, particularly China. For many Chinese people, social networking sites are a valuable opportunity to involve people in political activism and make purchases [73]. Mobile connectivity is offering Chinese people more chances to use social networking sites. As can be observed from the map, the other prolific Asian countries, in addition to China, are India with 41 articles, followed by South Korea (18 articles) and Indonesia (15 articles). The consistent number of articles may also be due to the increasingly important role of social networking sites as a marketing tool in Asian countries.

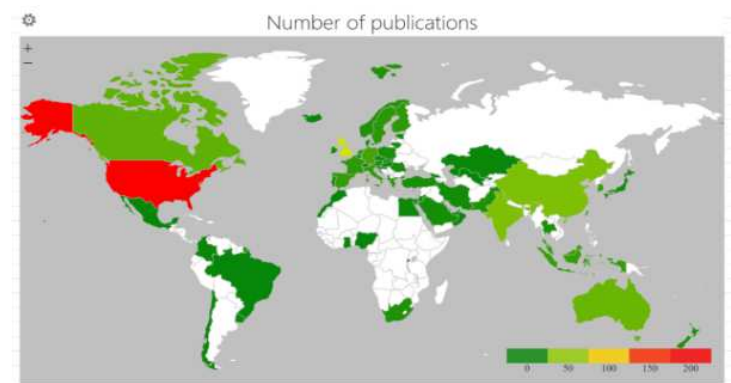

Figure 3. Global dispersion of social networking sites in relation to the literature on materialism and unsustainable consumer behavior.

\subsection{Analysis of Influential Authors}

This section analyzes the high-impact authors in the Scopus-indexed knowledge base on materialism, social networking sites and unsustainable consumer behaviour. It provides valuable insights for establishing patterns of knowledge generation and dissemination of social networking sites literature in relation to materialism and unsustainable consumer behaviour.

Table 2. Highly cited authors on social networking sites, materialism, and consumer behavior $(n=593)$.

\begin{tabular}{|c|c|c|c|c|c|c|}
\hline Rank & Author & Nation & Schools of Thought & Articles & Citations & Citations Per Document \\
\hline 1 & De Valck, K. & FRA & Social Media and Consumer Behavior & 1 & 856 & 856 \\
\hline 2 & Kozinets, R. V. & USA & Digital Marketing and Online Consumption & 1 & 856 & 856 \\
\hline 3 & Wilner, S. J. S. & CAN & Social Media and Consumer Behavior & 1 & 856 & 856 \\
\hline 4 & Wojnicki, A. C. & USA & Digital Marketing and Online Consumption & 1 & 856 & 856 \\
\hline 5 & Habibi, M. R. & USA & Digital Marketing and Online Consumption & 4 & 616 & 154 \\
\hline 6 & Laroche, M. & CAN & Digital Marketing and Online Consumption & 4 & 616 & 154 \\
\hline 7 & Richard, M. O. & USA & Digital Marketing and Online Consumption & 4 & 616 & 154 \\
\hline 9 & Goh, K. Y. & SIN & Digital Marketing and Online Consumption & 1 & 516 & 516 \\
\hline 10 & Heng, C. S. & SIN & Social Media and Consumer Behavior & 1 & 516 & 516 \\
\hline 11 & Xiang, Z. & $\mathrm{CHI}$ & Tourism and Social Media & 2 & 431 & 215.5 \\
\hline 12 & Gummerus, J. & FIN & Social Media and Consumer Behavior & 1 & 359 & 359 \\
\hline 13 & Labrecque, L. I. & USA & Social Media and Consumer Behavior & 2 & 359 & 179.5 \\
\hline 14 & Liljander, V. & FIN & Social Media and Consumer Behavior & 1 & 359 & 359 \\
\hline 15 & Pihlström, M. & FIN & Social Media and Consumer Behavior & 1 & 359 & 359 \\
\hline 18 & Schwartz, Z. & USA & Tourism and Social Media & 1 & 260 & 260 \\
\hline 19 & Uysal, M. & USA & Tourism and Social Media & 1 & 260 & 260 \\
\hline 20 & Hofacker, C. F. & USA & Digital Marketing and Online consumption & 3 & 222 & 856 \\
\hline
\end{tabular}


Table 2 shows that Habibi (four articles), Laroche (four articles), Richard (four articles), Wang (four articles), Lin (three articles) and Hofacker (three articles) are the most productive scholars according to the number of Scopus documents examined in the area of social networking sites in relation to unsustainable consumer behaviour and materialism. However, as observed in Table 2, if the criteria are changed, and authors ranked according to the overall number of citations received to rate the high-impact authors, De Valck, Kozinets, Wilner, and Wojnicki (856 citations), Habibi, Laroche, and Richard (616 citations), and Lin (518 citations) are the most highly cited authors. It should be noted that these highly cited authors tend to focus on several disciplines of social networking sites; many focus on electronic word of mouth and the impact of online reviews and user-generated content on consumer behaviour (De Valck and Wojnicki). Others appear to study the effects of paid social networking sites marketing on users (Kozinets, Habibi, and Lin). The remaining verge toward broader digital advertising and online consumer behaviour (Laroche, Richard, and Wilner).

\subsection{Intellectual Structure of the Literature}

In this part of the paper, the authors illustrate the "intellectual structure" of the social networking sites literature in relation to the body of literature on materialism and consumer behaviour knowledge. The authors carried out an author co-citation analysis (ACA), displayed with a figure that depicts the relations between highly co-cited authors. The study of co-citation assumes that strongly co-cited authors carry some form of intellectual similarity [74]. Figure 4 shows the author co-citation map. Nodes represent units of analysis, in this case, scholars, and network ties represent similarity connections. The size of the nodes indicates the number of co-citations received; the bigger the node the more co-citations they have received. Adjacent nodes are considered intellectually similar.

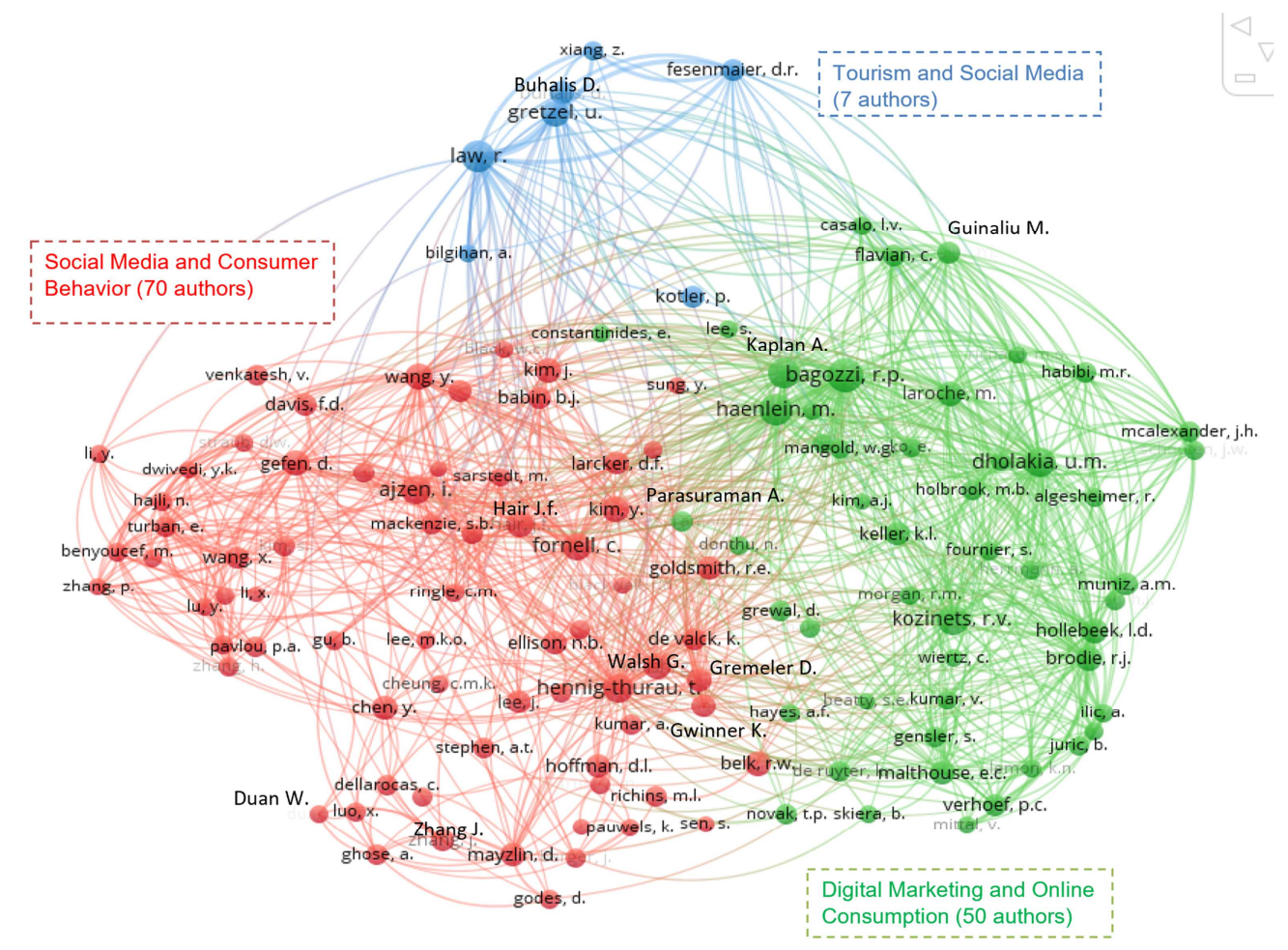

Figure 4. Three clusters representing the intellectual structure of the social networking sites literature.

Scholars belonging to the green cluster (Digital Marketing and Online Consumption) have extensively published on digital marketing tools and how these impact online sales. These tools also negatively affect consumer behaviours, such as buying more impulsively or conspicuously because of highly customized digital advertising campaigns. Digital marketing covers a wide range of topics, including evolving business models using emerging technologies, reducing costs and growing the industry internationally in an intensely competitive marketplace.

The red cluster (Social Media and Consumer Behavior) instead highlights scholars who have focused their attention on traditional consumer behavior concepts, such as brand management, brand equity, and consumer attitudes toward purchases, and how these theories have been impacted by the widespread usage of social networking sites. Seventy authors belong to this group, and the top co-cited are Kaplan (114 cocitations), Hennig-thurau (108 co-citations), and Ajzen (103 co-citations). The last cluster is related to social media and tourism, a niche topic with a growing community of scholars. Seven authors belong to this school of thought. They focus on how social networking sites can influence consumer 
behaviours in the tourism industry through word of mouth, online reviews, and user-generated content [75].

Author co-citation analysis (ACA) revealed that the conceptual landscape of materialism and unsustainable consumption behaviours in the social media context comprises three Schools of Thought. One school (Digital Marketing and Online Consumption, which consisted of authors whose scholarship provides the intellectual underpinnings for understanding how re-targeting and other paid ads strategies adopted in the social networking environments may enhance, especially in users with high levels of materialism, unsustainable consumption behaviours in particular impulse buying behaviour. Retargeting on social media is a personalized type of online advertising based on a user's browsing history. These customized "recommendations" highlight the same items that the user was browsing before leaving a website and have a high chance of being purchased, potentially boosting sales. The strategy has been conceived as consumers who search for goods online often leave a website without purchasing and do not return. The messages conveyed have high relevancy with the preferences of the users which is highly is more likely to make an unplanned purchase.

The red and blue clusters were more directly concerned with consumer behaviour concepts: attitudes towards advertisement, purchase intention and social proof and how these well-established theories have adapted and have been used within the social media domain. Social proof within this cluster was mentioned as a driving force for social media users with high levels of materialism that are inspired by other users to make purchases through emulation and conspicuous purchase. Social networking sites users tend to follow influencers and to purchase more products or services promoted by them. This is because they perceive influencers as more genuine and trustworthy [91]. By usually posting positive images of themselves, users want to solicit belongingness and positive feedback from their online reference group of peers. Therefore, attitudes towards usergenerated content combined with high usage of social networking sites can enhance conspicuous and impulse buying behaviours.

The emergence of these schools of thought through cocitation analyses could not have been predicted prior to this review. While there were exceptions, authors in the blue cluster focused more narrowly on the tourism industry unsustainable consumption behaviours. Only scholars in the Red and Green cluster consistently addressed the full range of processes associated with social media, materialism and unsustainable consumption behaviours.

\section{Discussion}

The results of this systematic literature review regarding materialism, social networking sites, and unsustainable consumption behaviours show that social media sites provide outlets for customers to access, distribute, and exchange information of different kinds regarding products and experiences. Although the previous literature has documented the influence of traditional media on materialism $[30,75]$, research into the relationship between unsustainable consumption behaviours and materialism in social networking sites and digital context has been limited. Kamal, Chu [76] recently looked at this relation and discovered that customers appear to have higher rates of materialism when their social network usage intensity increases. Similarly, Bush and Gilbert [77] found that consumers who spend more time on social networking sites have higher materialism levels than those who spend time reading newspapers. While studying more recent research, it is necessary to understand that users build an identity that portrays themselves to encourage other users' engagement. Unlike television, social networking sites use occurs mainly individually and in more private environments. Social media discussions can be as genuine as people's conversations, therefore, the impact of advertising on consequential behavioural actions is more personal than that of television [78]. Because customers have constant access to social networking sites through smartphones, in different contextual settings of time, place, and even state of mind, messages from brands or users can reach users at any time. Unlike social networking sites environments, television watching prepares the audience by showing ads between shows. In contrast, social networking sites advertising messages have various degrees of ad placements, thus having a more profound impact on the users, depending on their emotional state of mind [79]. Thus, marketing methods on social networking sites target individual users directly, in an intimate and personal context, and may significantly impact their consumption habits by instilling materialistic needs, culminating in an increase in purchasing patterns.

The research studies show that compulsive buying is affected significantly by intense internet usage, particularly through social networking sites platforms [49]. Several researchers have grouped this behaviour into the general category of drug abuse-like addictive, harmful, and/or unpleasant behaviours [80]. Following the social comparison theory, the concept that one's self-idea is profoundly affected by what other people think dates back to over a century ago. Similarly, engagement with role models and/or membership in desirable networks significantly impacts social identity formation [81]. Some scholars have emphasized the need for greater empirical study to better understand the influence of these pervasive contexts on young people's identities by emphasizing the distinct impact of different social networking site platforms. According to Valkenburg and Peter [82], the context of social networking sites may impair young people' ability to establish a "unified" identity. This is because while dealing with various people in an online environment, young adults can develop numerous personalities. Identity confusion can result from this process, which is more commonly known as identity fragmentation [83]. This concept is built on the principle that individuals constantly compete to communicate their identity through consumption. As a result, if they do not consume, they can be 
thought of as having an "empty self" that needs to be "filled" through the material consumption of goods and services (i.e., their identity is formed from what they own/consume). Similarly, empirical research has shown that compulsive buying is seen in young people with a poorly developed sense of identity. They strive to obtain fulfilment through constant goods purchases, supporting this empty-selfconcept.

Empirical research and theoretical models on the impact of materialism over conspicuous consumption among social networking sites users is scarce [84]. The literature demonstrates a strong positive association between television viewing and materialistic consumption behaviours [85]. Following the same concept, other research has assumed that the frequency of social networking sites usage can lead consumers to make irrational choices by increasing their expenditure on luxury goods (i.e., conspicuous use) [5, 29]. Similarly, on social networking sites accounts, consumers share products and brands that display wealth and satisfy a person's need for prestige [12]. Users may not only identify with advertising content and characters picked by young people as role models, but they may also desire to mimic them in terms of how they dress or behave, which can impact what young people buy. As a result, it is suggested that social networking sites may encourage conspicuous buying behaviour, increasing the likelihood that consumers prefer to acquire things with a high perceived status. Individual actions, particularly impulse buying behaviour, are strongly influenced by social networking sites [14]. Users of social networking sites have a broad spectrum of opinions, ranging from what they want to accomplish that day to a critical assessment of the goods and services they consume [86]. Customers who persuade others by sharing photographs of their transactions and providing comments tend to influence this behaviour. This emphasis is placed on impulsive and unexpected purchases.

Furthermore, instructions and perspectives impact buying habits and generate positive brand image, which enhances impulse purchase stimulation [87]. Shoppers use social networking site knowledge to generate new ideas, which can subsequently be converted into purchasing activities; for example, after viewing a clothing item on social networking sites, customers can search for it online or in an actual store and purchase it. Furthermore, past research has shown that information from other users is the most meaningful feedback on social networking sites due to recommendations and images displaying [75]. Consequently, social networking sites can be used as a tool to encourage people to shop and as a stimulus to make them want to buy something without thinking about it.

\subsection{Advertising Content in Social Networking Sites and Relation with Unsustainable Consumption Behaviors}

One relevant factor in the literature explaining the relation between materialism and unsustainable consumption behaviors in social networking sites is the role played by advertisement. Previous research on television advertisements revealed that ads trigger unsustainable consumption patterns, such as compulsive buying behavior, especially among young adults [87]. In previous studies, advertisements have also been found to positively influence impulse-buying behavior because ads in social networking sites are intended to stimulate a desire for certain products or services [88]. Social networking sites usage and viewership are directly linked with increased impulse-buying behavior among adolescents. Zafar [89] found that there is a positive relation between attitudes toward social networking sites advertisements and conspicuous buying behavior. Social networking sites advertisements aim to create a culture that encourages the audience to seek success, happiness, status, and popularity, in addition to embracing social stereotypes. Buijzen and Valkenburg [90] conducted a study of adolescents and found that social networking sites advertisements have both short- and long-term effects on impulse and compulsive buying behavior.

In the study by Jin and Ryu [91], in which user-generated posts of Instagram influencers were analyzed, envy toward the images portrayed among users had a positive impact on buying intention among male consumers. This positive relation was even stronger in selfies. In addition, the relation between social networking sites user-generated content envy and higher impulse purchase intention was stronger in males than in females. This finding implies that males are more competitive, especially when it comes to attitude toward same-sex others, which presumably triggers impulse-buying behavior for the envied products. This also resonates with the evolutionary perspective on males' stronger intrasexual competition [92]. Different factors that impact unsustainable behaviors in a virtual environment that must be taken into account are the ease of access to goods, page or profile content quality, and virtual cues [93]. These are some of the factors that can be attributed to enhanced impulse-buying behavior as a positive response to social networking sites advertising content [94]. In the online world, impulse purchasing is prevalent [94] due to wider product versatility, extended product lines, quicker transactions, and advertisement personalization. The prevalence of ecommerce also promotes the ease of making purchases. Moreover, the wide availability of e-commerce goods and services also comes at reduced prices [95]. All these factors can persuade individuals to engage in impulse-buying behavior. According to Charoennan and Huang [96], conspicuous purchases and, in general, the consumption of luxury goods is no longer characteristics of a privileged lifestyle. Conspicuous buying behavior has become increasingly frequent and significant in mass culture as a result of the rising use of social networking sites. Consumers can now share their purchases experiences thanks to technology improvements [96]. Posting a product or an exclusive service on social networking sites, according to Duan and Dholakia [97], can be regarded as new type of ostentatious conduct because users are exposing their own affluence in an attempt to retain or increase social status by openly showing the consumption of their goods. 
Materialism, according to the literature, can also act as a mediator of unsustainable behaviors. Materialistic persons, according to Gilovich and Gallo [98], spend more time watching adverts and are more likely to enjoy advertising materials. It has been shown that persons who enjoy adverts are more likely to engage in impulse purchase behavior on social networking sites [99]. There have been research [62] that link materialism to behavioral addictions (notably, pathological gambling and addictive buying). In recent years, the link between material possession and unsustainable buying behavior has emerged as one of the most essential and promising areas of addictive buying research. Unsustainable spending is defined as a chronic behavioral style with a strong impulsive-compulsive component that uses purchase as the best approach to deal with bad emotions and to try to achieve more satisfying cognitive-emotional states [100]. In addition to other determining elements such as anxiety, depression, impulsiveness, and impulse control, empirical evidence frequently reveals that materialism is positively connected with acquisitive disorders [28]. Furthermore, materialism is a strong predictor of compulsive shopping [101]. However, materialism has traditionally been viewed as an antecedent variable, of stress, anxiety, depression, and emotional control [102] proposed as mediator variables between materialism and addictive buying.

\subsection{Future Research Agenda}

This systematic review presented an integrative understanding of materialism and social networking sites on unsustainable consumption behaviours. Future research should pay more attention to the effects of social networking sites advertisements regarding users' cognition, affections, attitudes, and reactions to these ads [103]. Although this is an area of significant interest to advertisers, few academic studies have cross-culturally analyzed specific ads to gain more generalizable insights from a consumer habits perspective [104].

From the body of literature, a general empirical overview of how companies and organizations advertise on social networking sites and how those ads are created appears to be missing. Therefore, it would be helpful to explore, more generally, the kinds of products or brands that are advertised on social networking sites, the types of advertising messages used, and the response of users to advertisements on social networking sites. Social scientists should pay more attention to potential synergies between social networking sites and traditional offline marketing methods, such as newspapers or billboards, because traditional marketing tools are increasingly making direct reference to their social networking sites pages through, for example, QR codes. This relation may corroborate the unsustainable consumption habits of users, who are impacted by promotional messages more frequently and with consistent intensity.. The following are specific primary research questions for researchers: How can brand communication in social networking sites affect offline buying behaviour; is the combination of digital and non-digital media successful in influencing interaction with brands on social networking sites; if social networking sites are combined with other media, which processes influence customer responses toward such cross-media capacities?

Another domain that is worth exploring is social networking sites influencers which are becoming more popular. While using influencers to promote products and services takes advantage of the unique nature of social networking sites, academic research on the harmful effects of influencers on users' consumption is limited [105]. Social networking sites influencers can be compared to other types of endorsers who already have a strong foundation of academic experiences, such as celebrities or experts. The fact that social networking sites influencers are more similar than celebrities to social networking sites users they target makes them more trustworthy and authentic because social networking sites users assume they generate real content; therefore, users may be inclined to purchase more than they usually would do [106]. Future research should examine what factors influence people's perceptions of social media influencers as overly commercial or unacceptable and how this influences customer responses to the advocated brand. De Veerman, Cauberghe, and Hudders [107] discovered that social networking site influencers generally engage selected niches, and practitioners frequently distinguish between micro (small but with a considerable reach) and macro (large with a major reach) influencers (over 100,000 followers and a well-established personality and content). Future research should investigate whether micro and macro-influencers elicit distinct responses and, if so, what processes explain these discrepancies.

Studies are needed on the forms of personalization that are crucial for brands on social networking platforms. Personalization variables that can only be noticed through social networking sites should be studied rather than personalization based on gender and age, which may be applied across all media. A first approach could be to methodically map whatever variables marketers are currently employing to tailor their social networking site messages and how this influences user behaviour.

Surprisingly, ethical concerns surrounding social networking site marketing and advertising have received less attention in prestigious journals. Future studies should focus on solutions to support customers who deal with the hidden persuasive intent of brand engagement on social media platforms, as well as data-collection procedures. According to regulations [108], consumers must be clearly notified about the commercial nature of sponsored posts on social networking platforms. Future research should look into whether offering other sorts of information about advertising or data-collection activities, such as disclaimers, might help consumers cope with this practice. Future research might look into how privacy issues and privacy protection policies impact customer responses to data-driven brand communication, as well as what the boundaries are. Future research should investigate whether adolescents comprehend the persuasive intent of advertisement strategies on social media and the ramifications of data gathering procedures, 
given that minors are active users of these sites.

Future research should focus not only on the adverse effects on customers but also on the potential brand consequences. Recent Facebook controversies involving the breach of millions of users' privacy could have repercussions for firms that use social networking sites as a platform. Future research looking into the impact of privacy violations, fake news, and other misleading content on people's trust in social networking sites and brand communication will be beneficial.

It may be helpful in future research to rely less heavily on Facebook as a research context; while Facebook is by far the most popular social networking site platform, it differs in many ways from other platforms, and new social networking sites appear regularly. Future research should focus on Instagram and new messenger services, and it should compare various social networking sites platforms more frequently.

Regarding the research methods applied, most of the studies examined used online surveys with convenience samples. Although this data collection method may be appropriate for the subject studied, there are significant shortcomings that need to be considered and that prevent conclusions about causality being reached [109]. Most of the studies referred to correlational survey data rather than data collected through a panel or experimental designs. Consequently, it is often impossible to tell cause from effect or whether correlations are merely spurious. Future studies should use fewer student samples. Many of the studies referred to convenience samples of university students. Although students represent large proportions of social networking sites users [110], they are not representative of the entire population of social networking sites users. Therefore, the results may not be generalizable.

Previous research has shown that people's attitudes toward advertising may differ depending on education and age, and less educated and younger people have reported more favourable attitudes toward advertisements [111]. These findings may also apply to social networking sites networking advertisements. The authors believe that consumers' attitudes toward social networking sites advertising and user-generated content differ between countries. Therefore, as observed in our bibliometric review, social networking sites advertisements and their consequential impact on unsustainable consumption behaviours have been understudied, and more research should be carried out in the future. Furthermore, most studies have dealt with social networking sites usage and factors that drive purchase intentions that create value and revenue for companies. However, few studies have focused on the negative and unsustainable behaviours developed by social networking sites as a consequence of more targeted ads.

\subsection{Limitations}

There are limitations to every study. The authors used Scopus as a source of studies; however, publications that were not indexed in the chosen database were excluded from this review. The findings of this systematic review should be used as a starting point for academic debate and study, not as a conclusion. As a result, the whole literature on social networking sites and unsustainable consumption practices are significantly more extensive than the scope of this study. The effect of this restriction was slightly minimized by the fact that co-citation research looks at all of the papers in the assessed database's reference lists. As a result, it covers a substantially more significant number of documents than Scopus. Finally, despite the mathematical precision of bibliometric analysis, reading co-citation maps is not always straightforward. According to Zupic and Cater [82], 'making sense of the output of co-citation analyses requires the scholar's prior knowledge of the literature.

The bibliometric literature review included an arbitrary selection of peer-reviewed journal articles that may not be fully representative of the state of existing knowledge, and the preference for some studies over others results in sample selection bias, which is a type of bias caused by selecting a non-random sample of data for further analysis. Several procedures, however, were implemented to eliminate article selection bias. The researchers clarified the topic under examination before developing a systematic review. Second, having a team of two researchers reduced the probability of missing critical selection components (such as selecting criteria for study inclusion/exclusion), which were subjected to a double assessment of each of the abstracts in the databases.

Keywords, cognate terms and sentinel articles used to identify the body of knowledge have been carefully chosen to reflect articles strictly referring to the domain of materialism, social networking sites and unsustainable consumption behaviours. The main drawback of this choice is that relevant articles, which may not directly belong to the domain of social networking sites and consumer behaviour, may have been excluded from this review. Therefore, we encourage future studies to consider a wider range of cognate terms and sentinel articles to increase the number of peer-reviewed documents to be included for review purposes.

Science mapping is a method for evaluating the structure of a knowledge base that is systematic and quantitative. However, this methodology does not substitute analysis methods that evaluate substantive results derived from research papers due to its reliance on "meta-data" correlated with documents that make up a body of information. With this in mind, the current review only sets the stage for future research syntheses that examine findings from studies on social networking sites and users' unsustainable consumption behaviours.

Our conceptual definitions of 'unsustainable consumption' present another constraint. Given the recency of this literature, a consensus on the construct's "conceptual limits" has yet to emerge. Scholars have approached unsustainable consumption behaviours from the perspectives of its effects on the environment, over labourer's and broader social implications, and the economic impact, there are still few research that studies the effects of unsustainable consumption 
on users' psychology. The limitation that arises from this feature of the literature lies in the ambiguity of the boundaries of the unsustainable consumption construct, and therefore, the operational criteria used to select documents for review. Given the fluidity of this literature's evolution, the authors dealt with this limitation at two levels. Conceptually, we adopted a perspective on unsustainable consumption behaviours' that did not give importance to a specific model. Secondly, while researching articles, we relied on multiple sets of keywords (i.e., unsustainable consumption and online consumer behaviour) to identify documents for inclusion.

\subsection{Conclusions}

The purpose of this bibliometric review is to track the role played by social media in relation to materialism and users' consumption behaviors within the existing literature. Materialism has become an important topic for sustainability researchers due to its impacts on the world economy, societies and environmental issues. Several studies have demonstrated a direct link between high materialism levels and compulsive, conspicuous, and impulse-buying behavior which are related to overconsumption, pollution, obesity, debts, social unrest among the many negative consequences. From the review it emerged that social networking sites are changing the consumption process of users. Social media are accessible all the times thanks to the widespread usage of smartphones, and its algorithms continuously propose users the most suitable products based on tracked online behaviors. This lead user to become constantly alert about new products or services available in market. This alertness may become an issue when users start connecting their happiness with worldly things which is a sign of materialism. Another point raised by the review relates to the changing culture of the societies; people have become busier with their careers, which results in making them susceptible towards worldly things and dependent on social media. The lack of physical social interaction is often compensated by acquiring material belongings or indulging into exclusive services that need to be showed in their social media account to generate envy in other users, this mechanism also is confirmed by the social comparison theory. Knowing this fact, marketers promote their products like chocolates, pizzas, motor bike, cars, laptop, and holiday tours as a prerequisite for celebrating festivals and success. For this purpose, they use influencers which are related to their targeted audience [99]. The message conveyed through social media ads and influencers alike helps portraying the communication advertised as perfect and desirable. As a result of this, users start relating their happiness with the advertised items, a clear sign of materialism. Materialistic attitude impacts social relations that ultimately results in conflicts and more selfish behaviors within societies. To overcome the effect of materialism, adequate consideration needs to be given by governments and policy makers to deflect the attention of users from heavy usage of social media. Being a primary control agent, governing bodies can impose social media platforms to reveal more information regarding their content moderators, algorithms and the way they target users. Therefore, social media policing plays an active role in reducing the negative consequence of materialism and consumption within social media platforms context.

\section{Funding}

This research received no external funding.

\section{Conflicts of Interest}

The authors declare no conflict of interest

\section{References}

[1] Schlosberg, D., From postmaterialism to sustainable materialism: the environmental politics of practice-based movements. Environmental Politics, 2019.

[2] Evers, U., et al., Exploring materialism and frugality in determining product end-use consumption behaviors. Psychology \& Marketing, 2018. 35 (12): p. 948-956.

[3] Dursun, I., Psychological barriers to environmentally responsible consumption, in Ethics, social responsibility and sustainability in marketing. 2019, Springer. p. 103-128.

[4] McClure, C. and Y.-K. Seock, The role of involvement: Investigating the effect of brand's social media pages on consumer purchase intention. Journal of Retailing and Consumer Services, 2020. 53: p. 101975.

[5] Rajković, B., et al., Gaining trust in the digital age: The potential of social media for increasing the competitiveness of small and medium enterprises. Sustainability, 2021. 13 (4): p. 1884 .

[6] Gupta, V., The influencing role of social media in the consumer's hotel decision-making process. Worldwide Hospitality and Tourism Themes, 2019.

[7] Singh, C. and L. Ang, Persuasive effects in social media: the case of envy. International Journal of Advertising, 2020: p. 125 .

[8] Ismail, A. R., B. Nguyen, and T. C. Melewar, Impact of perceived social media marketing activities on brand and value consciousness: roles of usage, materialism and conspicuous consumption. International Journal of Internet Marketing and Advertising, 2018. 12 (3): p. 233-254.

[9] Mähönen, J. and J. T. Cullen, Taming unsustainable finance: The perils of modern risk management. 2019.

[10] Joshua, J., The environmental effects of overconsumption, in The Economics of Addictive Behaviours Volume IV. 2017, Springer. p. 67-73.

[11] Pradhan, D., D. Israel, and A. K. Jena, Materialism and compulsive buying behaviour: The role of consumer credit card use and impulse buying. Asia Pacific Journal of Marketing and Logistics, 2018.

[12] Podoshen, J. S. and S. A. Andrzejewski, An examination of the relationships between materialism, conspicuous consumption, impulse buying, and brand loyalty. Journal of Marketing Theory and Practice, 2012. 20 (3): p. 319-334. 
[13] Czarnecka, B. and B. Schivinski, Do consumers acculturated to global consumer culture buy more impulsively? The moderating role of attitudes towards and beliefs about advertising. Journal of Global Marketing, 2019. 32 (4): p. 219238 .

[14] Aragoncillo, L. and C. Orus, Impulse buying behaviour: an online-offline comparative and the impact of social media. Spanish Journal of Marketing-ESIC, 2018.

[15] Chen, J. V., B.-c. Su, and A. E. Widjaja, Facebook $\mathrm{C}_{2}$ C social commerce: A study of online impulse buying. Decision Support Systems, 2016. 83: p. 57-69.

[16] Thoumrungroje, A., A cross-national study of consumer spending behavior: The impact of social media intensity and materialism. Journal of International Consumer Marketing, 2018. 30 (4): p. 276-286.

[17] Chu, S.-C., S. Kamal, and Y. Kim, Re-examining of consumers' responses toward social media advertising and purchase intention toward luxury products from 2013 to 2018: A retrospective commentary. Journal of Global Fashion Marketing, 2019. 10 (1): p. 81-92.

[18] Lulandala, E. E., Facebook Data Breach: A Systematic Review of Its Consequences on Consumers' Behaviour Towards Advertising. Strategic System Assurance and Business Analytics, 2020: p. 45-68.

[19] Media, B. F., https://www.bluefountainmedia.com/blog/2019year-review-blue-fountain-media. Archived on 25/02/2021.

[20] Blühdorn, I., Sustaining the unsustainable: Symbolic politics and the politics of simulation. Environmental politics, 2007. 16 (2): p. 251-275.

[21] Verma, A. K., Sustainable development and environmental ethics. International Journal on Environmental Sciences, 2019. 10 (1): p. 1-5.

[22] Kammerlander, M., et al., How does a social practice perspective add to the development of policy instruments to reduce consumption-based $\mathrm{CO}_{2}$ emissions? A case study of Austria. Climate Policy, 2020. 20 (3): p. 323-340.

[23] Chatzidakis, A., A. Smith, and S. A. Hibbert, “... Do I need it, do I, do I really need this?": Exploring the Role of Rationalization in Impulse Buying Episodes. ACR North American Advances, 2009.

[24] Connolly, J. and A. Prothero, Sustainable consumption: consumption, consumers and the commodity discourse. Consumption, Markets and culture, 2003. 6 (4): p. 275291.

[25] Shaw, D. and C. Moraes, Voluntary simplicity: an exploration of market interactions. International Journal of Consumer Studies, 2009. 33 (2): p. 215-223.

[26] O'Guinn, T. C. and R. J. Faber, Compulsive buying: A phenomenological exploration. Journal of consumer research, 1989. 16 (2): p. 147-157.

[27] Belk, R. W., Materialism: Trait aspects of living in the material world. Journal of Consumer research, 1985. 12 (3): p. 265-280.

[28] Churchill Jr, G. A. and G. P. Moschis, Television and interpersonal influences on adolescent consumer learning. Journal of consumer research, 1979. 6 (1): p. 23-35.
[29] Csikszentmihalyi, M. and E. Halton, The meaning of things: Domestic symbols and the self. 1981: Cambridge university press.

[30] Richins and Dawson, A consumer values orientation for materialism and its measurement: Scale development and validation. Journal of consumer research, 1992. 19 (3): p. 303316.

[31] Kasser, T. and A. Ahuvia, Materialistic values and well-being in business students. European journal of social psychology, 2002. 32 (1): p. 137-146.

[32] Shrum, L. J., et al., Reconceptualizing materialism as identity goal pursuits: Functions, processes, and consequences. Journal of Business Research, 2013. 66 (8): p. 1179-1185.

[33] Vedder, A. V., Social Problems in America, Costs and Casualties in an Acquisitive Society by Harry C. Bredemeier and Jackson Toby. New York, London: John Wiley and Sons, Inc. 1963.510 pp. \$3.95. 1964, Taylor \& Francis.

[34] Moschis, G. P. and G. A. Churchill Jr, Consumer socialization: A theoretical and empirical analysis. Journal of marketing research, 1978. 15 (4): p. 599-609.

[35] Belk, R. W., Acquiring, possessing, and collecting: fundamental processes in consumer behavior. Marketing theory: Philosophy of science perspectives, 1982: p. 185-190.

[36] Kasser, T. and R. M. Ryan, Further examining the American dream: Differential correlates of intrinsic and extrinsic goals. Personality and social psychology bulletin, 1996. 22 (3): p. 280-287.

[37] O'Neil, D. J., Explaining the Amish. International Journal of Social Economics, 1997.

[38] Millar, M. and R. Thomas, Discretionary activity and happiness: The role of materialism. Journal of Research in Personality, 2009. 43 (4): p. 699-702.

[39] Tsang, J.-A., et al., Why are materialists less happy? The role of gratitude and need satisfaction in the relationship between materialism and life satisfaction. Personality and individual differences, 2014. 64: p. 62-66.

[40] Cleveland, M., M. Laroche, and N. Papadopoulos, Cosmopolitanism, consumer ethnocentrism, and materialism: An eight-country study of antecedents and outcomes. Journal of International marketing, 2009. 17 (1): p. 116-146.

[41] Griffin, M., B. J. Babin, and F. Christensen, A cross-cultural investigation of the materialism construct: Assessing the Richins and Dawson's materialism scale in Denmark, France and Russia. Journal of Business Research, 2004. 57 (8): p. 893-900.

[42] Eastman, J. K., et al., The relationship between status consumption and materialism: A cross-cultural comparison of Chinese, Mexican, and American student. Journal of Marketing Theory and Practice, 1997. 5 (1): p. 52-66.

[43] Wong, A., Y. Chung, and J. L. Zaichkowsky, Understanding Luxury Brands in Hong Kong. European Advances in Consumer Research, (4), 1999: p. 310-316.

[44] Lerman, D. and S. Maxwell, Joining a consumer society: Russian immigrant versus American materialism. Journal of Consumer Behaviour: An International Research Review, 2006. 5 (6): p. 479-490. 
[45] Sharif, S. P. and J. Khanekharab, Identity confusion and materialism mediate the relationship between excessive social network site usage and online compulsive buying. Cyberpsychology, Behavior, and Social Networking, 2017. 20 (8): p. 494-500.

[46] Festinger, L., A theory of social comparison processes. Human relations, 1954. 7 (2): p. 117-140.

[47] Dittmar, H. and J. Drury, Self-image-is it in the bag? A qualitative comparison between "ordinary" and "excessive" consumers. Journal of economic psychology, 2000. 21 (2): p. 109-142.

[48] Xu, Y., The influence of public self-consciousness and materialism on young consumers' compulsive buying. Young consumers, 2008.

[49] d'Astous, A., An inquiry into the compulsive side of "normal" consumers. Journal of consumer policy, 1990. 13 (1): p. 1531 .

[50] Dittmar, H., Compulsive buying-a growing concern? An examination of gender, age, and endorsement of materialistic values as predictors. British journal of psychology, 2005. 96 (4): p. 467-491.

[51] Faber, R. J., Self-control and compulsive buying. 2004.

[52] Mazalin, D. and S. Moore, Internet use, identity development and social anxiety among young adults. Behaviour Change, 2004. 21 (2): p. 90

[53] Nunes, J. C., X. Drèze, and Y. J. Han, Conspicuous consumption in a recession: Toning it down or turning it up? Journal of Consumer Psychology, 2011. 21 (2): p. 199-205.

[54] Taylor, D. G. and D. Strutton, Does Facebook usage lead to conspicuous consumption? Journal of Research in Interactive Marketing, 2016

[55] Veblen, T., Conspicuous Leisure and Conspicuous Consumption. The Theory of the Leisure Class: An Economic Study of Institutions. New York: Macmillan, 1899. 43: p. 4445 .

[56] Rook, D. W., The buying impulse. Journal of consumer research, 1987. 14 (2): p. 189-199.

[57] Xiang, L., et al., Exploring consumers' impulse buying behavior on social commerce platform: The role of parasocial interaction. International journal of information management, 2016. 36 (3): p. 333-347.

[58] Dawson, S. and M. Kim, External and internal trigger cues of impulse buying online. Direct Marketing: An International Journal, 2009.

[59] Shoham, A. and M. M. Brenčič, Compulsive buying behavior. Journal of consumer marketing, 2003.

[60] Moher, D., et al., Preferred reporting items for systematic reviews and meta-analyses: the PRISMA statement. Int J Surg, 2010. 8 (5): p. 336-341.

[61] Zupic, I. and T. Čater, Bibliometric methods in management and organization. Organizational Research Methods, 2015. 18 (3): p. 429-472.

[62] Falagas, M. E., et al., Comparison of PubMed, Scopus, web of science, and Google scholar: strengths and weaknesses. The FASEB journal, 2008. 22 (2): p. 338-342.
[63] Kitchenham, B. and S. Charters, Guidelines for performing systematic literature reviews in software engineering. 2007.

[64] Leite, P. L., et al., Psychotherapy for compulsive buying disorder: A systematic review. Psychiatry research, 2014. 219 (3): p. 411-419.

[65] Memushi, A., Conspicuous consumption of luxury goods: literature review of theoretical and empirical evidences. International Journal of Scientific \& Engineering Research, 2013. 4 (12): p. 250-255.

[66] Alves, H., C. Fernandes, and M. Raposo, Social media marketing: a literature review and implications. Psychology \& Marketing, 2016. 33 (12): p. 1029-1038.

[67] Small, H., Co-citation in the scientific literature: A new measure of the relationship between two documents. Journal of the American Society for information Science, 1973. 24 (4): p. 265-269.

[68] Lamberton, C. and A. T. Stephen, A thematic exploration of digital, social media, and mobile marketing: Research evolution from 2000 to 2015 and an agenda for future inquiry. Journal of Marketing, 2016. 80 (6): p. 146-172.

[69] Chen, Q., et al., Social media policies as responses for social media affordances: The case of China. Government information quarterly, 2016. 33 (2): p. 313-324.

[70] Nerur, S. P., A. A. Rasheed, and V. Natarajan, The intellectual structure of the strategic management field: An author $\mathrm{co}^{-}$ citation analysis. Strategic Management Journal, 2008. 29 (3): p. $319-336$

[71] Shin, S. and Z. Xiang, Social Media-Induced Tourism: A Conceptual Framework. E-review of Tourism Research, 2020. 17 (4).

[72] Ger, G. and R. W. Belk, Accounting for materialism in four cultures. Journal of Material Culture, 1999. 4 (2): p. 183-204.

[73] Kamal, S., S.-C. Chu, and M. Pedram, Materialism, attitudes, and social media usage and their impact on purchase intention of luxury fashion goods among American and Arab young generations. Journal of Interactive Advertising, 2013. 13 (1): p. $27-40$.

[74] Bush, V. D. and F. W. Gilbert, The web as a medium: an exploratory comparison of internet users versus newspaper readers. Journal of Marketing Theory and Practice, 2002. 10 (1): p. $1-10$

[75] Fournier, S. and J. Avery, The uninvited brand. Business horizons, 2011.54 (3): p. 193-207.

[76] Joyce, N. and J. Harwood, Improving intergroup attitudes through televised vicarious intergroup contact: Social cognitive processing of ingroup and outgroup information. Communication Research, 2014. 41 (5): p. 627-643.

[77] Wang, Advertising engagement: A driver of message involvement on message effects. Journal of Advertising Research, 2006. 46 (4): p. 355-368.

[78] Tajfel, H., Human groups and social categories: Studies in social psychology. 1981: Cup Archive.

[79] Valkenburg, P. M. and J. Peter, Online communication among adolescents: An integrated model of its attraction, opportunities, and risks. Journal of adolescent health, 2011. 48 (2): p. 121-127. 
[80] Israelashvili, M., T. Kim, and G. Bukobza, Adolescents' overuse of the cyber world-Internet addiction or identity exploration? Journal of Adolescence, 2012. 35 (2): p. 417 424.

[81] Sharma, P., B. Sivakumaran, and R. Marshall, Impulse buying and variety seeking: A trait-correlates perspective. Journal of Business Research, 2010. 63 (3): p. 276-283.

[82] Kim, A. J. and K. K. P. Johnson, Power of consumers using social media: Examining the influences of brand-related usergenerated content on Facebook. Computers in Human Behavior, 2016. 58: p. 98-108.

[83] Buijzen, M. and P. M. Valkenburg, Parental mediation of undesired advertising effects. Journal of Broadcasting \& Electronic Media, 2005. 49 (2): p. 153-165.

[84] Yang, H. and D. J. Ganahl. A cross-cultural study between American and Chinese college students regarding television viewing, materialism, beliefs and attitude toward advertising. 2004.

[85] Zafar, A. U., et al., The impact of social media celebrities' posts and contextual interactions on impulse buying in social commerce. Computers in Human Behavior, 2019: p. 106178.

[86] Opree, S. J., M. Buijzen, and P. M. Valkenburg, Lower life satisfaction related to materialism in children frequently exposed to advertising. Pediatrics, 2012. 130 (3): p. e486-e491.

[87] Jin, S. V. and E. Ryu, "I'll buy what she's\# wearing": The roles of envy toward and parasocial interaction with influencers in Instagram celebrity-based brand endorsement and social commerce. Journal of Retailing and Consumer Services, 2020. 55: p. 102121.

[88] Buunk, A. P. and K. Massar, Intrasexual competition among males: Competitive towards men, prosocial towards women. Personality and Individual Differences, 2012. 52 (7): p. 818821.

[89] Buunk, A. P. and M. Fisher, Individual differences in intrasexual competition. Journal of Evolutionary Psychology, 2009. 7 (1): p. 37-48.

[90] Wells, J. D., V. Parboteeah, and J. S. Valacich, Online impulse buying: understanding the interplay between consumer impulsiveness and website quality. Journal of the Association for Information Systems, 2011. 12 (1): p. 3.

[91] Srinivasan, S. S., R. Anderson, and K. Ponnavolu, Customer loyalty in e-commerce: an exploration of its antecedents and consequences. Journal of retailing, 2002. 78 (1): p. 41-50.

[92] Grandon, E. E. and J. M. Pearson, Electronic commerce adoption: an empirical study of small and medium US businesses. Information \& management, 2004. 42 (1): p. $197-$ 216.

[93] Charoennan, W. and K.-P. Huang, The antecedents and consequences of conspicuous consumption of luxury fashion goods in a social media platform. International Journal of Organizational Innovation (Online), 2018. 11 (1): p. 1-21.

[94] Kastanakis, M. N. and G. Balabanis, Explaining variation in conspicuous luxury consumption: An individual differences' perspective. Journal of Business Research, 2014. 67 (10): p. 2147-2154.
[95] Ki, C. W. and Y. K. Kim, Sustainable versus conspicuous luxury fashion purchase: Applying self-determination theory. Family and Consumer Sciences Research Journal, 2016. 44 (3): p. 309-323.

[96] Duan, J. and R. R. Dholakia, Posting purchases on social media increases happiness: the mediating roles of purchases' impact on self and interpersonal relationships. Journal of Consumer Marketing, 2017.

[97] Gilovich, T. and I. Gallo, Consumers' pursuit of material and experiential purchases: A review. Consumer Psychology Review, 2020. 3 (1): p. 20-33.

[98] Sharma, B. K., S. Mishra, and L. Arora, Does Social Medium Influence Impulse Buying of Indian Buyers? Journal of Management Research, 2018. 18 (1): p. 27-36.

[99] Ger, G. and R. W. Belk, Cross-cultural differences in materialism. Journal of economic psychology, 1996. 17 (1): p. 55-77.

[100] Banerjee, R. and H. Dittmar, Individual differences in children's materialism: The role of peer relations. Personality and Social Psychology Bulletin, 2008. 34 (1): p. 17-31.

[101] Dittmar, H. and P. Kapur, Consumerism and well-being in India and the UK: Identity projection and emotion regulation as underlying psychological processes. Psychological Studies, 2011. 56 (1): p. 71-85.

[102] Fennis, B. M. and W. Stroebe, Softening the blow: Company self-disclosure of negative information lessens damaging effects on consumer judgment and decision making. Journal of business ethics, 2014. 120 (1): p. 109-120.

[103] Muk, A., What factors influence millennials to like brand pages? Journal of Marketing Analytics, 2013. 1 (3): p. 127137.

[104] Domingues Aguiar, T. and E. van Reijmersdal, Influencer marketing. 2018: AmsterdamStichting Wetenschappelijk Onderzoek Commerciële Communicatie, SWOCC.

[105] De Veirman, M., V. Cauberghe, and L. Hudders, Marketing through Instagram influencers: the impact of number of followers and product divergence on brand attitude. International journal of advertising, 2017. 36 (5): p. 798-828.

[106] Boerman, S. C., L. M. Willemsen, and E. P. Van Der Aa, "This post is sponsored": Effects of sponsorship disclosure on persuasion knowledge and electronic word of mouth in the context of Facebook. Journal of Interactive Marketing, 2017. 38: p. 82-92.

[107] Zechmeister, E. B., J. J. Shaughnessy, and J. S. Zechmeister, A practical introduction to research methods in psychology. 1996: McGraw-Hill Humanities Social.

[108] Sashittal, H. C., R. Sriramachandramurthy, and M. Hodis, Targeting college students on Facebook? How to stop wasting your money. Business Horizons, 2012. 55 (5): p. 495-507.

[109] Shavitt, S., P. Lowrey, and J. Haefner, Public attitudes toward advertising: More favorable than you might think. Journal of advertising research, 1998. 38 (4): p. 7-22.

[110] Boateng, H. and A. F. Okoe, Consumers' attitude towards social media advertising and their behavioural response. Journal of Research in Interactive Marketing, 2015. 